\title{
Transcultural Diabetes Nutrition Therapy Algorithm: The Asian Indian Application
}

\author{
Shashank R. Joshi • V. Mohan • S. S. Joshi • \\ Jeffrey I. Mechanick $\cdot$ Albert Marchetti
}

Published online: 22 February 2012

(C) Springer Science+Business Media, LLC 2012

\begin{abstract}
India and other countries in Asia are experiencing rapidly escalating epidemics of type 2 diabetes (T2D) and cardiovascular disease. The dramatic rise in the prevalence of these illnesses has been attributed to rapid changes in demographic, socioeconomic, and nutritional factors. The rapid transition in dietary patterns in India - coupled with a sedentary lifestyle and specific socioeconomic pressures - has led to an increase in obesity and other diet-related noncommunicable diseases. Studies have shown that nutritional interventions significantly enhance metabolic control and weight loss. Current clinical practice guidelines (CPGs) are not portable to diverse cultures, constraining the applicability of this type of practical educational instrument. Therefore, a transcultural
\end{abstract}

S. R. Joshi $(\square)$

Department of Endocrinology Grant Medical College and Sir J J

Group of Hospitals, Lilavati Hospital, Bhatia Hospital, Joshi Clinic,

B23 Kamal Pushpa, 6, Bandra Reclamation, Bandra West,

Mumbai 400050, India

e-mail: Shashank.sr@gmail.com

\section{Mohan}

Dr. Mohan's Diabetes Specialities Centre \& Madras Diabetes

Research Foundation,

Chennai, India

S. S. Joshi

Mumbai Diet and Health Centre, Joshi Clinic Bandra,

Mumbai, India

J. I. Mechanick

Division of Endocrinology, Diabetes, and Bone Disease,

Mount Sinai School of Medicine,

New York, NY, USA

\section{A. Marchetti}

Department of Preventive Medicine and Public Health, University of Medicine and Dentistry of New Jersey,

Newark, NJ, USA
Diabetes Nutrition Algorithm (tDNA) was developed and then customized per regional variations in India. The resultant Indiaspecific tDNA reflects differences in epidemiologic, physiologic, and nutritional aspects of disease, anthropometric cutoff points, and lifestyle interventions unique to this region of the world. Specific features of this transculturalization process for India include characteristics of a transitional economy with a persistently high poverty rate in a majority of people; higher percentage of body fat and lower muscle mass for a given body mass index; higher rate of sedentary lifestyle; elements of the thrifty phenotype; impact of festivals and holidays on adherence with clinic appointments; and the role of a systems or holistic approach to the problem that must involve politics, policy, and government. This Asian Indian tDNA promises to help guide physicians in the management of prediabetes and T2D in India in a more structured, systematic, and effective way compared with previous methods and currently available CPGs.

Keywords Asian Indians · Diabetes · Nutrition therapy

\section{Introduction}

The transcultural Diabetes Nutrition Algorithm (tDNA) is being developed under the direction of an international panel of expert health care professionals. The tDNA is intended to 1) increase awareness of the benefits of nutritional interventions for patients with prediabetes and type 2 diabetes (T2D); 2) encourage healthy eating practices that accommodate regional differences in lifestyles, foods, and cultures; 3 ) enhance the implementation of existing clinical practice guidelines (CPGs) for prediabetes and T2D management; and 4) simplify nutritional therapy for patients with prediabetes and T2D by facilitating global application and portability. The tDNA represents a consensus of highly experienced practitioners, researchers, 
and academicians and is supported by evidence and opinion that were rated based on scientific substantiation, according to the standards expressed in the American Association of Clinical Endocrinologists "Protocol for Standardized Production of Clinical Practice Guidelines-2010 Update" [1]. Customization per regional variations in dietary habits, culture, lifestyle, body mass index (BMI), and other parameters was initiated as a part of the first regional conference in India.

India and other countries in Asia (Note: throughout the text: "Southeast Asian" refers to natives of India, Pakistan, and Bangladesh; "Asian Indian" refers to people who resided in India and migrated to East and South Africa, the United Kingdom, Singapore, Indonesia, and the United States; "East Asian" refers to people living in China, Korea, Taiwan, etc.; and the term "South Asian" is more generic than "Southeast Asian" or "Asian Indian") are experiencing rapidly escalating epidemics of T2D and cardiovascular disease (CVD). This dramatic rise in T2D has been attributed to rapid changes in demographic, socioeconomic, and nutritional factors. These epidemiologic, nutritional, financial, and social transitions are characteristic for "transitional economies." According to the Diabetes Atlas 5 [2], India currently has the second largest number of people with T2D in the world; this has been confirmed by a recent national study [3]. The Indian Council of Medical ResearchIndia Diabetes (ICMR-INDIAB) study [3, 4] is a communitybased survey conceived with the aim of identifying prevalence rates of T2D in India as a whole (covering all 28 states, the National Capital Territory of Delhi, and 2 of the union territories in the mainland of India), in a phased manner, with a total proposed sample size of 124,000 individuals. According to the first phase results of this study - done in four states of India representing north, south, east, and west, and covering a population of 218 million people - there are currently 62.4 million people with T2D and 77.2 million people with prediabetes [3]. Multiple logistic regression analysis showed that age, male gender, family history of T2D, urban residence, abdominal obesity, generalized obesity, hypertension, and income status were significantly associated with T2D. Significant risk factors for prediabetes were age, family history of $\mathrm{T} 2 \mathrm{D}$, abdominal obesity, hypertension, and income status.

This review highlights key forces that have incited transitions in India, increased the burden of T2D in India, and led to the transculturalization required for an Asian Indian tDNA development. Furthermore, this review demonstrates the importance of the Asian Indian tDNA in primary, secondary, and tertiary $\mathrm{T} 2 \mathrm{D}$ prevention strategies.

\section{Epidemiologic Transitions to Noncommunicable Diseases}

Demographic and associated economic and sociologic changes induce complex shifts in health, disease states, and mortality rates. In transition economies, especially in developing countries such as India, infectious and communicable diseases are being replaced by chronic degenerative or metabolic noncommunicable diseases (NCDs) as the primary causes of morbidity and mortality [5]. This epidemiologic transition in India contributes to premature deaths in adults, particularly in urban areas [6]. There is also emerging evidence for infective agents in the development of chronic diseases, as shown by raised concentrations of inflammatory markers [7]. Studies from India support the view that urbanization increases the levels of certain cytokines and contributes in some measure to the urban-rural differences in NCD risk [8].

On the one hand, when Asian Indian migrants adopt the lifestyles - including the dietary patterns and broad sociocultural practices - of the indigenous population, they take on the disease patterns of the native population as well. Conversely, following migration, a genetic predisposition to the risk of early-onset adult NCDs can be unmasked. One specific example of the interplay between environmental and genetic factors is the increased risk of T2D and NCDs among Asian Indian migrants to the United Kingdom [9]. Another important feature of the developmental transition in India is the rapid urbanization and large population shifts from rural to urban areas [6].

The impact of nutritional transitions and related metabolic disorders has been regarded as diet-related noncommunicable diseases by a consensus group formed for revising previous dietary guidelines for India. The rapid nutritional transition observed in India results in excess consumption of calories, saturated fats, trans fatty acids, simple sugars, and salt, with low intake of fiber, monounsaturated fatty acids, and n-3 polyunsaturated fatty acids. This dietary pattern, coupled with sedentary behaviors, promotes obesity, T2D, and CVD in both urban and rural areas [10]. This phenomenon has recently been confirmed by the first phase results of the ICMR-INDIAB study [3].

\section{Fetal Origins Hypothesis in India and Its Role in Diabetes}

The susceptibility to T2D may be conferred by evolutionary enrichment of thrifty genes, which long ago enhanced survival during periods of famine, but have now created detriment with conditions of plentiful food and sedentary lifestyles [11]. An alternative explanation that has been recently proposed is the thrifty phenotype hypothesis (subsequently generalized as fetal origins), which links the obesity and T2D epidemic to an unfavorable intrauterine environment $[12,13]$. This thinking is based on certain observations of an inverse relationship between birth weight and risk of T2D and metabolic syndrome (MS) in elderly populations. 
Asians, as a group, have small body size. Women from the rural parts of India are small and are thought to be chronically undernourished because of their low BMI. Iron and other nutrient deficiencies are very common in this group. Indian babies are the smallest in the world; onethird are born with low birth weight (LBW; $<2.5 \mathrm{~kg}$ ) [14]. Thus, it is possible that maternal and fetal undernutrition contribute to the T2D epidemic in Asian countries [15]. In Indians, T2D is diagnosed at least a decade earlier and individuals are considerably thinner than their UK counterparts [15]. Indians have thinner limbs, which is suggestive of smaller muscle mass. However, despite their thinness, they are centrally obese, with higher waist-hip ratio (WHR) and higher subscapular-triceps skinfold ratio than their UK counterparts [15]. Many studies show that Indians have more body fat for any given BMI compared with Caucasians and black Africans $[16,17]$. Indians also have higher levels of central obesity (measured as waist circumference [WC], WHR, visceral fat, and posterior subcutaneous abdominal fat). This is reflected in higher plasma nonesterified fatty acid and triglyceride concentrations, hyperinsulinemia with fasting as well as post-glucose challenge states, and higher insulin resistance [18]. Thus, Indians have an unusual thin-fat body composition associated with the insulin resistance syndrome.

The Pune Maternal Nutrition Study [19, 20] has given insight into fetal development in Indian populations. This prospective, population-based, observational research assessed rural Indian women and their offspring. Mothers were short and thin (mean pre-pregnant height and BMI: $152 \mathrm{~cm}$ and $18.1 \mathrm{~kg} / \mathrm{m}^{2}$, respectively); mean full-term birth weight was only $2.7 \mathrm{~kg}$. Detailed anthropometry of the newborns showed that their body composition differed from white Caucasian babies born in the United Kingdom. The Indian babies were lighter by almost 2 standard deviations (SDs), and lean tissues such as muscle (mid-upper arm circumference) and abdominal viscera (abdominal circumference) showed a similar deficit. However, truncal fat (subscapular skinfolds) was relatively spared $(-0.5 \mathrm{SD})$. Thus, although extremely small and thin, the babies had relatively increased adiposity. A similar pattern is seen in urban Indian adults. It has been suggested that increasing maternal parity predicts increasing adiposity in the newborn infant. This may result from maternal nutritional, cardiovascular, or immunologic factors $[19,20]$.

\section{Nutrition Transition and Increased Risk of T2D}

Epidemiologic, nutritional, and economic transitions have also revealed certain trends and patterns in the nutritional transition in India. A hectic lifestyle and the easy availability of convenience foods have led to irregular meals and frequent snacking on energy-dense fast foods, including ready-to-use gravies and soups, packaged salty snacks, ready-made cookies, and commercial fast foods, rather than traditional homecooked food. Furthermore, consumption of animal foods, sugar (especially sweetened, carbonated beverages), and traditional Indian energy-dense foods has also increased. The diets of all income groups have moved away from wholegrain cereals to other food groups, with greater shifts noted among the urban populations and the higher-income groups [10].

India progressed toward caloric adequacy in the $1970 \mathrm{~s}$ and early 1980s, as documented by the National Nutrition Monitoring Bureau [21] and other surveys. The surveys showed a gradual improvement in caloric intake per capita, typified by an increase in consumption of cereal grains, while the intake of most other food items-such as milk, oil, sugar, etc.--remained largely unchanged. However, many of these surveys revealed disparities in the intakes of most foods between rural and urban populations and between different socioeconomic groups. Comparison of food consumption patterns shows a gradual reduction in cereal grain consumption between 1975 and 1995 that has not affected the average energy intake. This is largely the result of a progressive increase in the intake of protein and, likely, fats. The latter is due to a significant increase in the consumption of milk and other dairy products, as well as an increase in the intake of animal products (designated flesh foods), fats, and oils. The production of pulses and legumes is also a concern; consequently, their cost and consumption have fallen dramatically. This is somewhat worrisome because pulses and legumes were once a very important source of vegetable proteins in the traditional Indian diet. Trends in the changes in consumption of urban populations are not readily available, although the surveys conducted between the late 1970s and the 1990s show wide differences between the socioeconomic strata in an urban environment. One would have expected these disparities to have widened further over the years, although this is not evident from the data [21].

While carbohydrates remain the major source of energy in Indian diets, the percentage of total energy intake derived from carbohydrates has declined (1975-1979, 80.3\%; 2001, $75.5 \%$ ); however, the quality of carbohydrates has changed from the traditional high-fiber carbohydrates to the low-fiber carbohydrates such as polished white rice, which has a higher glycemic index. There is also an increase in the percentage of energy coming from dietary fats $(1975-1979,8.9 \% ; 2001$, $13.9 \%$ ). However, the proportion of dietary energy coming from fat still remains less than $15 \%$, which is lower than the recommended dietary allowance of $15 \%$ to $30 \%$ [22]. Consumption of oils, fats, and animal products has increased in almost all the states [21]. Energy intake is lower in urban areas, in spite of higher intake of fats and oils, because of 
lower cereal consumption compared with rural areas [23]. Reasons for these dichotomous observations of decreased energy intake with rising prevalence of obesity could be under-reporting of dietary consumption data [23], higher energy intake compared with energy expenditure [24], and increasingly sedentary lifestyles [21-24].

\section{Regional Disparities in India}

India is a diverse country covering 28 states, the National Capital Region of Delhi, and several union territories in the mainland of India. Regional disparities in prediabetes and $\mathrm{T} 2 \mathrm{D}$ are common, attributable to the vast variation in culture and dietary habits across regions. In an attempt to understand these variations and disparities, there has been an explosion in T2D epidemiology studies in India over the past 20 years [25]. In the large cities of north and south India (Chennai [26-28], Trivandrum [29, 30], Mumbai [31], Delhi [32, 33], Jaipur [34], and Gauhati [35]), in large metropolises [36], and in industrial populations [37], T2D prevalence among adults ( $>20$ years of age) has ranged from $8 \%$ to $15 \%$. Within urban populations, a large heterogeneity of T2D prevalence is noted, depending on the socioeconomic stratum studied and sampling response rates.

There are few epidemiological studies in semi-urban India $[38,39]$, and many in rural populations $[40,41]$. In earlier years, there was a very low prevalence of $\mathrm{T} 2 \mathrm{D}$ in rural populations. However, recent studies from Maharashtra [42] and Andhra Pradesh [43] report very high prevalence rates similar to those in urban Indian populations. Interestingly, a significant correlation of BMI with T2D has been observed in these studies. It has been hypothesized that although there is a significant increase in T2D as populations move from rural to semi-urban to urban and cosmopolitan habitats, a reverse migration of culture may already be taking place in Indian rural populations. Earlier rural-urban disparities in T2D could be due to a low prevalence of overweight and obesity in rural, compared to urban, subjects [44].

The recent ICMR-INDIAB study [3] has featured the regional disparities more prominently, with the first phase results stating that in 2011, Maharashtra will have 6 million individuals with T2D and 9.2 million with prediabetes; Tamilnadu will have 4.8 million people with T2D and 3.9 million with prediabetes; Jharkhand will have 0.96 million people with T2D and 1.5 million with prediabetes; and Chandigarh will have 0.12 million people with T2D and 0.13 million with prediabetes. With greater urbanization, growth of the middle class, and aging of the population, tremendous increases in the numbers of people with T2D in India are projected in the future [3].

In south India, rice is the staple food, and highly polished white rice has been linked to T2D [45, 46] and MS [47]. The ICMRINDIAB study may help to throw more light on the role of dietary factors in the differences in $\mathrm{T} 2 \mathrm{D}$ and prediabetes prevalence rates.
Studies confirm that risk factors tend to develop early in the life cycle in Indian subjects; consequently, T2D occurs at least 10 to 15 years earlier than it does in people of non-Indian origin [48]. The generalized and central obesity levels at which T2D occurs are also lower in Indian subjects compared with Caucasian populations [49]. For Southeast Asians and Asian Indians, a waist size of greater than $90 \mathrm{~cm}$ in men and greater than $80 \mathrm{~cm}$ in women is now accepted as a major risk factor for T2D and other CVD risk factors of MS [50]. The influence of societal affluence levels on T2D prevalence in India suggests that a global solution with the greatest impact on reducing the T2D epidemic lies with policy makers and governments [51]. There is a need to change the economic/environmental structure and culture in urban areas of India so that physical activity and healthy dietary choices are available [52].

\section{Trends and Transition in Obesity}

Obesity has increased rapidly in many populations in recent years [53-55] due to an interaction between genetic and environmental factors. These include metabolic characteristics $[51,52,56]$, physical inactivity [57-59], habitual energy intake in relation to expenditure, and macronutrient composition of the diet [60-64]. The increases in obesity prevalence have been accompanied by concomitant increases in T2D prevalence [56]; so much so that an etiological connection between the two seems obvious. Data from the Nurses' Health study suggest that the lowest risk of T2D occurs in individuals who have a BMI less than $21 \mathrm{~kg} / \mathrm{m}^{2}$, with increasing prevalence seen as obesity levels increase [56]. Those with higher BMIs have much higher incidence rates of T2D at earlier ages than those with lower BMIs, among whom the incidence rises in the older age groups. Several studies indicate that WC or WHR may be a better indicator of the risk of developing diabetes than BMI [65-67]. Such data suggest that the distribution of body fat is an important determinant of risk, as these measures reflect abdominal or visceral obesity.

A recent review has shown higher risks for Asians compared with Caucasians for the development of obesity and obesity-related NCDs (OR-NCDs), including insulin resistance, MS, T2D, and CVD [68]. Differences in determinants and associated factors for OR-NCDs between Asian Indians and Caucasians include body phenotype (high body fat; high truncal, subcutaneous and intra-abdominal fat; and low muscle mass), biochemical parameters (hyperinsulinemia, hyperglycemia, dyslipidemia, hyperleptinemia, low levels of adiponectin, and high levels of C-reactive protein), procoagulant state, and endothelial dysfunction [69, 70]. Epidemiologic research has demonstrated an association between low muscle mass and increased insulin resistance [71], which may relate to phenotype, aging with muscle wasting, low dietary protein intake, or insufficient resistance training. Higher prevalence, 
earlier onset, and increased occurrence of T2D and CVD are often seen at lower levels of BMI and WC in Asian Indians than in Caucasians. Given the importance of central adiposity as a determinant of T2D risk, it is necessary to consider whether the usually quoted normal range for BMI $\left(18.5-24.9 \mathrm{~kg} / \mathrm{m}^{2}\right)$ is appropriate for all populations. Lower cutoffs for obesity and abdominal obesity have been advocated for Asian Indians (BMI: overweight $>23$ to $24.9 \mathrm{~kg} / \mathrm{m}^{2}$ and obesity $\geq 25 \mathrm{~kg} / \mathrm{m}^{2}$; $\mathrm{WC}$ : men $\geq 90 \mathrm{~cm}$ and women $\geq 80 \mathrm{~cm}$, respectively). A minimal rise in the BMI or WC would act adversely in a subject with a genetic susceptibility to T2D. Studies in India have shown that central obesity was more strongly associated with glucose intolerance than generalized obesity was [68].

In urban India, data show a prevalence of obesity of $10 \%$ and $15.1 \%$ (2003) [72]; 20.8\% and 32.3\% (2004) [73]; and $43.2 \%$ and $47.4 \%$ (2007) in men and women, respectively [74]. Interestingly, a high prevalence has been reported in economically disadvantaged adults residing in urban slums (14\%) [32], specifically in postmenopausal women (28\%) [75]. An increased prevalence of obesity has also been reported in rural areas from 8\% reported in 1997 [76] to $32.4 \%$ in men and $41.4 \%$ in women in 2007 [77]. Of particular concern, childhood obesity is also increasing from $16 \%$ in 2002 to about 24\% in 2006 in North India [78], and from $4.9 \%$ in 2003 to $6.6 \%$ in 2005 in South India [79].

\section{Trends and Transition in Physical Inactivity}

Numerous studies have indicated the importance of physical inactivity in the development T2D [80, 81]. In the Nurses' Health Study [81], women who reported exercising vigorously had an age-adjusted incidence rate of self-reported, clinically diagnosed T2D that was two thirds as high as that of women who exercised less frequently. The deleterious effect of low levels of physical activity is seen particularly among those subjects who have other risk factors, such as high BMI, hypertension, or parental T2D. Similarly, among male physicians, the incidence of self-reported T2D was negatively related to the frequency of vigorous exercise, and the strength of this relationship was greater in those with higher BMI [80]. For equivalent degrees of obesity, more physically active subjects have a lower incidence of the disease [82].

Several studies have shown that Asian Indians are more sedentary than Caucasians [83]. For example, findings from the Newcastle Heart Project (comprising Asian Indians $[n=$ $105]$ and Europeans $[n=416])$ showed that Asian Indians are less physically active than Europeans. Similarly, another UK study showed that lower physical activity in Asian Indians, Pakistanis, or Bangladeshis, compared with their European counterparts, was inversely correlated with BMI, WC, systolic blood pressure, plasma glucose, and plasma insulin levels [84]. The prevalence of T2D and impaired glucose tolerance has been shown to be significantly lower in higher quartiles of physical activity in South Indians (ie, 17.0\%, 9.7\%, and 5.6\% for sedentary, moderately heavy, and heavy physical activity, respectively) [85]. It is believed that a sedentary lifestyle is an important factor contributing to the development of T2D and CVD in Asian Indians [86, 87]. The Consensus Development Group for formulating the Consensus Physician Activity Guidelines for Asian Indians considered the available physical activity guidelines from international and Indian studies and formulated the following India-specific guidelines.

A total of $60 \mathrm{~min}$ of physical activity per day is recommended for healthy Asian Indians, in view of the high predisposition to develop T2D and CVD. This should include at least $30 \mathrm{~min}$ of moderate-intensity aerobic activity, $15 \mathrm{~min}$ of work-related activity, and $15 \mathrm{~min}$ of muscle-strengthening exercises. For children, moderate-intensity physical activity for 60 min daily should be in the form of sports and physical activity. This consensus statement also includes physical activity guidelines for pregnant women, the elderly, and those suffering from obesity, T2D, CVD, and other components of MS. Proper application of guidelines is likely to have a significant impact on the prevalence and management of these cardiometabolic factors in Asian Indians [88].

Studies have looked at a community-based participatory research approach to translate the original Diabetes Prevention Program in the United States into one that is age-specific and culture-specific for other regions of the world. These studies have evaluated cultural strategies for healthy behaviors, including culture-specific physical activities, knowledge and access to healthy foods, physical activity for youth and their parents, interactive hands-on learning activities for healthy lifestyles, and group formats for adopting healthy behaviors [89].

\section{Barriers to Clinical Management}

Sociocultural and religious factors influence health beliefs, diet, and lifestyle management in Asian Indians [90-92]. Cultural factors (eg, festivals and holidays) contribute to a greater frequency of missed clinic appointments by Asian Indians compared with Caucasians. Furthermore, poor adherence with T2D therapy (insulin or oral agents) is common among Asian Indians during holidays, and glycemic control is unsatisfactory due to religious fasting [93-95]. Asian Indian patients with T2D also tend to have a more negative attitude and tend to believe they were made to wait longer in clinics than UK Caucasians do [96]. Response to drugs has been suspected to be different in Asian Indians compared with Caucasians, but this phenomenon has not been adequately investigated. Prevalence of associated conditions such as dyslipidemia, hypertension, and CVD is also affected by differences in body fat composition, dietary changes, abdominal obesity, and BMI [69]. A recent study showed that 
self-efficacy is an important factor in determining outcomes [97]. In contrast, an advantageous sociocultural factor seen in Asian Indians is the extended family structure, often helping patients to cope better with insulin therapy and morbidities.

\section{Asian Indian Holistic Approach Toward Management of Prediabetes and T2D}

The enormous social and personal cost of T2D makes a compelling case for prevention. In view of the evidence and the devastating health impact of cardiometabolic disease, it seems prudent that primary prevention should be a major priority. The greatest hope lies in implementing lifestyle intervention programs on a large scale, targeting multiple nodes in a complex cultural network or system, buttressed by a favorable political and regulatory strategy, and initially focused on high-risk persons. Meta-analysis studies [98] looking at T2D education and a variety of weight loss methods have shown that nutrition interventions have the largest statistically significant effect on metabolic control and weight loss. In addition, these meta-analyses have shown that T2D education, in general, is effective in improving knowledge, skills, psychosocial adjustment, and metabolic control. Overall, the evidence involving medical nutrition therapy in $\mathrm{T} 2 \mathrm{D}$ management supports nutritional intervention.

\section{Conclusions}

Many developing countries, including India, now report the onset of T2D at increasingly younger ages. This trend toward younger age of onset implies a huge additional burden to the affected individuals and to society, and necessitates a lifetime approach to prevention and treatment. To achieve maximal benefit from lifestyle interventions, changes in governmental policies and legislation will be needed, in addition to individual and community-based programs. Thus, evidence-based advice to governments and public health authorities must emphasize the role of weight reduction in the overweight and obese, nutritional interventions, and modified focused lifestyle interventions. This approach can also be expected to have a positive effect on the prevention of other major NCDs, such as CVD and hypertension. The tDNA focuses on interventions in prediabetes and $\mathrm{T} 2 \mathrm{D}$, taking into consideration the regional differences across various cultures, and focuses on comorbidities and interventions at all levels. Efforts for an Asian Indian customization that will reflect various physiologic, nutritional, epidemiologic, pathologic, and anthropometric factors, as well as nutritional and cultural factors, are in progress and will be incorporated into the algorithm template. The goal of this initiative is to provide guidance to physicians in the management of prediabetes and T2D in a much more structured, systematic, and effective way.
Acknowledgments The authors would like to thank the following members of the Task Force for Development of Transcultural Algorithms in Nutrition and Diabetes: Osama Hamdy, MD, Joslin Diabetes Center, Harvard University, Boston, MA, USA; Caroline Apovian, $\mathrm{MD}$, Nutrition and Weight Management Center, Boston University School of Medicine, Boston, MA, USA; Alexander Benchimol, MD, Obesity and Eating Disorders Group, State Institute of Diabetes and Endocrinology of Rio de Janeiro, Rio de Janeiro, Brazil; Peter Bisschop, MD, Division of Endocrinology and Metabolism, Academic Medical Center, University of Amsterdam, Amsterdam, The Netherlands; Alexis Bolio-Galvis, MD, Department of General and Bariatric Surgery and Clinical Nutrition, Hospital Angeles Pedregal; Clinical Nutrition and General Surgery, Facultad Mexicana de Medicina, Universidad La Salle, Mexico City, Mexico; Osama Hamdy, MD, Joslin Diabetes Center, Harvard University, Boston, MA, USA; Refaat Hegazi, MD, Research \& Development, Abbott Nutrition, Columbus, OH, USA; David Jenkins, MD, Department of Nutritional Sciences, University of Toronto, Toronto, Ontario, Canada; Enrique Mendoza, MD, University of Panama School of Medicine, Panama City, Panama; Miguel Leon-Sanz, PhD, Service of Endocrinology and Nutrition, University Hospital Doce de Octubre, Madrid, Spain; Patrizio Tatti, PhD, Department of Endocrinology and Diabetology, ASL RMH, Rome, Italy.

Disclosure Conflicts of interest: The development of this article was funded by Abbott Nutrition. Shashank Joshi has received honoraria from Abbott Nutrition, sanofi-aventis, MSD, USV, Novartis, Bayer Zydus, Roche Diagnostics, Dexcom, LifeScan J\&J, BMS-Astra, Boehinger Ingelheim, NovoNordisk and Glenmark. Viswanathan Mohan has received financial support for consulting fees and travel to the meetings to develop this paper from Abbott Nutrition. He has also received support for consultancy from Novo Nordisk, LifeScan J\&J, MSD Pharmaceuticals, and USV. Dr. Mohan's institution has received financial support for grants from Novo Nordisk, LifeScan J\&J, MSD Pharmaceuticals, USV, Sanofi Aventis, Roche Diagnostics and Abbott Nutrition. His institution has also received honoraria from Novo Nordisk, LifeScan J\&J, MSD Pharmaceuticals, USV, Sanofi Aventis, Roche Diagnostics and Abbott Nutrition. Shilpa Joshi has received honoraria from Abbott Nutrition and USV. Albert Marchetti has received financial support for research and the development of educational materials from BMS, Abbott Nutrition, Takeda, and Eli Lilly. Jeffrey Mechanick has received financial support for the development of educational presentations from Abbott Nutrition. He has received financial support for consultancy and for writing and reviewing the manuscript from Abbott Nutrition. He has received fees for participation in review activities such as data monitoring boards, statistical analysis, and end point committees from Abbott Nutrition International. He has received funding for travel and accommodations from Abbott Nutrition.

\section{References}

1. Mechanick JI, Camacho PM, Cobin RH, Garber AJ, Garber JR, Gharib H, et al. American Association of Clinical Endocrinologists Protocol for Standardized Production of Clinical Practice Guidelines-2010 update. Endocr Pract.16:270-83.

2. International Diabetes Federation. One fifth of all adults with diabetes live in the South-East Asia region. 2011. http://www.idf.org/sites/ default/files/attachments/SEA-Press-Release-WDD.pdf. Accessed December 272011.

3. Anjana RM, Pradeepa R, Deepa M, Datta M, Sudha V, Unnikrishnan $\mathrm{R}$, et al. Prevalence of diabetes and prediabetes (impaired fasting glucose and/or impaired glucose tolerance) in urban and rural India: 
phase I results of the Indian Council of Medical Research-INdia DIABetes (ICMR-INDIAB) study. Diabetologia. 2011;54:3022-7.

4. Anjana RM, Pradeepa R, Deepa M, Datta M, Sudha V, Unnikrishnan $\mathrm{R}$, et al. The Indian Council of Medical Research-India Diabetes (ICMR-INDIAB) study: methodological details. J Diabetes Sci Technol. 2011;5:906-14.

5. Omran AR. The epidemiologic transition. A theory of the epidemiology of population change. Milbank Mem Fund Q. 1971;49: 509-38.

6. Shetty PS. Nutrition transition in India. Publ Health Nutr. 2002;5:17582 .

7. Ross R. Atherosclerosis-an inflammatory disease. N Engl J Med. 1999;340:115-26.

8. Yudkin JS, Yajnik CS, Mohamed-Ali V, Bulmer K. High levels of circulating proinflammatory cytokines and leptin in urban, but not rural, Indians. A potential explanation for increased risk of diabetes and coronary heart disease. Diabetes Care. 1999;22:363-4.

9. McKeigue PM. Cardiovascular disease and diabetes in migrants interactions between nutritional changes and genetic background. In: Shetty PS, McPherson K, editors. Diet, nutrition \& chronic disease: lessons from contrasting worlds. London: Wiley; 1997. p. 59-70.

10. Misra A, Sharma R, Gulati S, Joshi SR, Sharma V. Ghafoorunissa, et al. Consensus dietary guidelines for healthy living and prevention of obesity, the metabolic syndrome, diabetes, and related disorders in Asian Indians. Diabetes Technol Ther. 2011;13:683-94.

11. Neel JV. Diabetes mellitus: a "thrifty" genotype rendered detrimental by "progress"? Am J Hum Genet. 1962;14:353-62.

12. Barker DJ. Fetal origins of coronary heart disease. BMJ. 1995;311:1714.

13. Hales CN, Barker DJ. Type 2 (non-insulin-dependent) diabetes mellitus: the thrifty phenotype hypothesis. Diabetologia. 1992;35:595-601.

14. Yajnik CS. Early life origins of insulin resistance and type 2 diabetes in India and other Asian countries. J Nutr. 2004;134:205-10.

15. Yajnik CS. The insulin resistance epidemic in India: fetal origins, later lifestyle, or both? Nutr Rev. 2001;59:1-9.

16. Banerji MA, Faridi N, Atluri R, Chaiken RL, Lebovitz HE. Body composition, visceral fat, leptin, and insulin resistance in Asian Indian men. J Clin Endocrinol Metab. 1999;84:137-44.

17. Deurenberg P, Deurenberg-Yap M, Guricci S. Asians are different from Caucasians and from each other in their body mass index/ body fat per cent relationship. Obes Rev. 2002;3:141-6.

18. McKeigue PM, Shah B, Marmot MG. Relation of central obesity and insulin resistance with high diabetes prevalence and cardiovascular risk in South Asians. Lancet. 1991;337:382-6.

19. Fall C. Maternal nutrition: effects on health in the next generation. Indian J Med Res. 2009;130:593-9.

20. Joshi NP, Kulkarni SR, Yajnik CS, Joglekar CV, Rao S, Coyaji KJ, et al. Increasing maternal parity predicts neonatal adiposity: Pune Maternal Nutrition Study. Am J Obstet Gynecol. 2005;193:783-9.

21. National Nutrition Monitoring Bureau. Report of Second Repeat Surveys in Rural Area in NNMB States. NNMB Technical Report Number 18. Hyderabad, India. 1999.

22. National Institute of Nutrition. Dietary Guidelines for Indians: A Manual. National Institute of Nutrition, Indian Council of Medical Research. Hyderabad, India. 1998.

23. Livingstone MB, Black AE. Markers of the validity of reported energy intake. J Nutr. 2003;133 Suppl 3:895S-920S.

24. Stubbs CO, Lee AJ. The obesity epidemic: both energy intake and physical activity contribute. Med J Aust. 2004;181:489-91.

25. Verma NP, Mehta SP, Madhu S, Mather HM, Keen H. Prevalence of known diabetes in an urban Indian environment: the Darya Ganj diabetes survey. Br Med J (Clin Res Ed). 1986;293:423-4.

26. Mohan V, Deepa M, Deepa R, Shanthirani CS, Farooq S, Ganesan $\mathrm{A}$, et al. Secular trends in the prevalence of diabetes and impaired glucose tolerance in urban South India-the Chennai Urban Rural Epidemiology Study (CURES-17). Diabetologia. 2006;49:1175-8.
27. Mohan V, Mathur P, Deepa R, Deepa M, Shukla DK, Menon GR, et al. Urban rural differences in prevalence of self-reported diabetes in India-the WHO-ICMR Indian NCD risk factor surveillance. Diabetes Res Clin Pract. 2008;80:159-68.

28. Mohan V, Shanthirani S, Deepa R, Premalatha G, Sastry NG, Saroja R. Intra-urban differences in the prevalence of the metabolic syndrome in southern India - the Chennai Urban Population Study (CUPS No. 4). Diabet Med. 2001;18:280-7.

29. Joseph A, Kutty VR, Soman CR. High risk for coronary heart disease in Thiruvananthapuram city: a study of serum lipids and other risk factors. Indian Heart J. 2000;52:29-35.

30. Kutty VR, Soman CR, Joseph A, Pisharody R, Vijayakumar K. Type 2 diabetes in southern Kerala: variation in prevalence among geographic divisions within a region. Natl Med J India. 2000;13: 287-92.

31. Iyer SR, Iyer RR, Upasani SV, Baitule MN. Diabetes mellitus in Dombivli-an urban population study. J Assoc Phys India. 2001;49:713-6.

32. Misra A, Pandey RM, Devi JR, Sharma R, Vikram NK, Khanna N. High prevalence of diabetes, obesity and dyslipidaemia in urban slum population in northern India. Int J Obes Relat Metab Disord. 2001;25:1722-9.

33. Prabhakaran D, Shah P, Chaturvedi V, Ramakrishnan L, Manhapra A, Reddy KS. Cardiovascular risk factor prevalence among men in a large industry of northern India. Natl Med J India. 2005; 18:59-65.

34. Gupta A, Gupta R, Sarna M, Rastogi S, Gupta VP, Kothari K. Prevalence of diabetes, impaired fasting glucose and insulin resistance syndrome in an urban Indian population. Diabetes Res Clin Pract. 2003;61:69-76.

35. Shah SK, Saikia M, Burman NN, Snehalatha C, Ramachandran A. High prevalence of type 2 diabetes in urban population in northeastern India. Int J Diab Dev Countries. 1999;18:97-101.

36. Ramachandran A, Snehalatha C, Kapur A, Vijay V, Mohan V, Das $\mathrm{AK}$, et al. High prevalence of diabetes and impaired glucose tolerance in India: National Urban Diabetes Survey. Diabetologia. 2001;44:1094-101.

37. Reddy KS, Prabhakaran D, Chaturvedi V, Jeemon P, Thankappan KR, Ramakrishnan L, et al. Methods for establishing a surveillance system for cardiovascular diseases in Indian industrial populations. Bull World Health Organ. 2006;84:461-9.

38. Ramachandran A, Jali MV, Mohan V, Snehalatha C, Viswanathan M. High prevalence of diabetes in an urban population in south India. BMJ. 1988;297:587-90.

39. Singh TP, Singh AD, Singh TB. Prevalence of diabetes mellitus in Manipur. In: Shah SK, editor. Diabetes update. Guwahati: North Eastern Diabetes Society; 2001. p. 13-9.

40. Patandin S, Bots ML, Abel R, Valkenburg HA. Impaired glucose tolerance and diabetes mellitus in a rural population in south India. Diabetes Res Clin Pract. 1994;24:47-53.

41. Wander GS, Khurana SB, Gulati R, Sachar RK, Gupta RK, Khurana $\mathrm{S}$, et al. Epidemiology of coronary heart disease in a rural Punjab population-prevalence and correlation with various risk factors. Indian Heart J. 1994;46:319-23.

42. Deo SS, Zantye A, Mokal R, Mithbawkar S, Rane S, Thakur K. To identify the risk factors for high prevalence of diabetes and impaired glucose tolerance in Indian rural population. Int J Diab Dev Countries. 2006;26:19-23.

43. Chow CK, Raju PK, Raju R, Reddy KS, Cardona M, Celermajer $\mathrm{DS}$, et al. The prevalence and management of diabetes in rural India. Diabetes Care. 2006;29:1717-8.

44. Luepkar RV, Evans A, McKeigue P, Reddy KS. Cardiovascular survey methods. 3rd ed. Geneva: World Health Organization; 2004.

45. Mohan V, Radhika G, Sathya RM, Tamil SR, Ganesan A, Sudha V. Dietary carbohydrates, glycaemic load, food groups and newly 
detected type 2 diabetes among urban Asian Indian population in Chennai, India (Chennai Urban Rural Epidemiology Study 59). Br J Nutr. 2009;102:1498-506.

46. Mohan V, Radhika G, Vijayalakshmi P, Sudha V. Can the diabetes/ cardiovascular disease epidemic in India be explained, at least in part, by excess refined grain (rice) intake? Indian J Med Res. 2010;131:369-72.

47. Radhika G, Van Dam RM, Sudha V, Ganesan A, Mohan V. Refined grain consumption and the metabolic syndrome in urban Asian Indians (Chennai Urban Rural Epidemiology Study 57). Metabolism. 2009;58:675-81.

48. Bhargava SK, Sachdev HS, Fall CH, Osmond C, Lakshmy R, Barker DJ, et al. Relation of serial changes in childhood bodymass index to impaired glucose tolerance in young adulthood. $\mathrm{N}$ Engl J Med. 2004;350:865-75.

49. Misra A, Vikram NK, Gupta R, Pandey RM, Wasir JS, Gupta VP. Waist circumference cutoff points and action levels for Asian Indians for identification of abdominal obesity. Int J Obes (Lond). 2006;30:106-11.

50. Alberti KG, Zimmet P, Shaw J. The metabolic syndrome-a new worldwide definition. Lancet. 2005;366:1059-62.

51. Rose G. The strategy of preventive medicine. New York: Oxford University Press; 1992.

52. Srinath Reddy K, Shah B, Varghese C, Ramadoss A. Responding to the threat of chronic diseases in India. Lancet. 2005;366:1744 9.

53. Kuczmarski RJ, Flegal KM, Campbell SM, Johnson CL. Increasing prevalence of overweight among US adults. The National Health and Nutrition Examination Surveys, 1960 to 1991. JAMA. 1994;272:205-11.

54. Life Sciences Research Office, Federation of American Societies for Experimental Biology, Interagency Board for Nutrition Monitoring and Related Research. Third Report on Nutrition Monitoring in the United States: Executive Summary. Centers for Disease Control and Prevention. 1995. http://www.cdc.gov/nchs/data/misc/ tronm.pdf. Accessed December 282011.

55. Shah M, Hannan PJ, Jeffery RW. Secular trend in body mass index in the adult population of three communities from the upper midwestern part of the USA: the Minnesota Heart Health Program. Int J Obes. 1991;15:499-503.

56. Colditz GA, Willett WC, Stampfer MJ, Manson JE, Hennekens $\mathrm{CH}$, Arky RA, et al. Weight as a risk factor for clinical diabetes in women. Am J Epidemiol. 1990;132:501-13.

57. Bouchard C, Tremblay A, Despres JP, Nadeau A, Lupien PJ, Theriault $\mathrm{G}$, et al. The response to long-term overfeeding in identical twins. N Engl J Med. 1990;322:1477-82.

58. Schoeller DA. The importance of clinical research: the role of thermogenesis in human obesity. Am J Clin Nutr. 2001;73:511-6.

59. World Health Organization, Food and Agriculture Organization. Preparation and Use of Food-Based Dietary Guidelines. Geneva, Switzerland. 1998. http://whqlibdoc.who.int/trs/WHO TRS 880. pdf. Accessed December 282011.

60. Flatt JP. Importance of nutrient balance in body weight regulation. Diabetes Metab Rev. 1988;4:571-81.

61. Grundy SM. Multifactorial causation of obesity: implications for prevention. Am J Clin Nutr. 1998;67:563S-72S

62. National Heart L, and Blood Institute. The lipid research clinics population studies data book: the prevalence study. Bethesda: National Institutes of Health; 1979.

63. Ravussin E, Swinburn BA. Pathophysiology of obesity. Lancet. 1992;340:404-8.

64. Shah M, Garg A. High-fat and high-carbohydrate diets and energy balance. Diabetes Care. 1996;19:1142-52.

65. Boyko EJ, Fujimoto WY, Leonetti DL, Newell-Morris L. Visceral adiposity and risk of type 2 diabetes: a prospective study among Japanese Americans. Diabetes Care. 2000;23:465-71.
66. Chan JM, Rimm EB, Colditz GA, Stampfer MJ, Willett WC. Obesity, fat distribution, and weight gain as risk factors for clinical diabetes in men. Diabetes Care. 1994;17:961-9.

67. Despres JP. Health consequences of visceral obesity. Ann Med. 2001;33:534-41.

68. Misra A, Khurana L. Obesity-related non-communicable diseases: South Asians vs White Caucasians. Int J Obes (Lond). 2011;35:16787.

69. Deepa R, Sandeep S, Mohan V. Abdominal obesity, visceral fat and Type 2 diabetes - "Asian Indian Phenotype". In: Mohan V, Gundu HRR, editors. Type 2 diabetes in South Asians: epidemiology, risk factors and prevention. New Delhi: Jaypee Brothers Medical; 2006. p. 138-52.

70. Joshi SR. Metabolic syndrome-emerging clusters of the Indian phenotype. J Assoc Phys India. 2003;51:445-6.

71. Srikanthan P, Karlamangla AS. Relative muscle mass is inversely associated with insulin resistance and prediabetes. Findings from the third National Health and Nutrition Examination Survey. J Clin Endocrinol Metab.96:2898-903.

72. Vikram NK, Pandey RM, Misra A, Sharma R, Devi JR, Khanna N. Non-obese (body mass index $<25 \mathrm{~kg} / \mathrm{m} 2$ ) Asian Indians with normal waist circumference have high cardiovascular risk. Nutrition. 2003;19:503-9.

73. Gupta R, Sarna M, Thanvi J, Rastogi P, Kaul V, Gupta VP. High prevalence of multiple coronary risk factors in Punjabi Bhatia community: Jaipur Heart Watch-3. Indian Heart J. 2004;56:646-52.

74. Deepa M, Farooq S, Deepa R, Manjula D, Mohan V. Prevalence and significance of generalized and central body obesity in an urban Asian Indian population in Chennai, India (CURES: 47). Eur J Clin Nutr. 2009;63:259-67.

75. Wasir JS, Misra A, Vikram NK, Pandey RM, Luthra K. C-reactive protein, obesity, and insulin resistance in postmenopausal women in urban slums of North India. Diab Met Syndr Clin Res Rev. 2007;1:83-9.

76. Chadha SL, Gopinath N, Shekhawat S. Urban-rural differences in the prevalence of coronary heart disease and its risk factors in Delhi. Bull World Health Organ. 1997;75:31-8.

77. Chow C, Cardona M, Raju PK, Iyengar S, Sukumar A, Raju R, et al. Cardiovascular disease and risk factors among 345 adults in rural India-the Andhra Pradesh Rural Health Initiative. Int J Cardiol. 2007;116:180-5.

78. Bhardwaj S, Misra A, Khurana L, Gulati S, Shah P, Vikram NK. Childhood obesity in Asian Indians: a burgeoning cause of insulin resistance, diabetes and sub-clinical inflammation. Asia Pac J Clin Nutr. 2008;17 Suppl 1:172-5.

79. Raj M, Sundaram KR, Paul M, Deepa AS, Kumar RK. Obesity in Indian children: time trends and relationship with hypertension. Natl Med J India. 2007;20:288-93.

80. Manson JE, Nathan DM, Krolewski AS, Stampfer MJ, Willett WC, Hennekens $\mathrm{CH}$. A prospective study of exercise and incidence of diabetes among US male physicians. JAMA. 1992;268:63-7.

81. Manson JE, Rimm EB, Stampfer MJ, Colditz GA, Willett WC, Krolewski AS, et al. Physical activity and incidence of non-insulindependent diabetes mellitus in women. Lancet. 1991;338:774-8.

82. Helmrich SP, Ragland DR, Leung RW, Paffenbarger Jr RS. Physical activity and reduced occurrence of non-insulin-dependent diabetes mellitus. N Engl J Med. 1991;325:147-52.

83. Kamath SK, Hussain EA, Amin D, Mortillaro E, West B, Peterson $\mathrm{CT}$, et al. Cardiovascular disease risk factors in 2 distinct ethnic groups: Indian and Pakistani compared with American premenopausal women. Am J Clin Nutr. 1999;69:621-31.

84. Hayes L, White M, Unwin N, Bhopal R, Fischbacher C, Harland J, et al. Patterns of physical activity and relationship with risk markers for cardiovascular disease and diabetes in Indian, Pakistani, Bangladeshi and European adults in a UK population. J Publ Health Med. 2002;24:170-8. 
85. Mohan V, Gokulakrishnan K, Deepa R, Shanthirani CS, Datta M. Association of physical inactivity with components of metabolic syndrome and coronary artery disease-the Chennai Urban Population Study (CUPS no. 15). Diabet Med. 2005;22:1206-11.

86. Knowler WC, Fowler SE, Hamman RF, Christophi CA, Hoffman HJ, Brenneman AT, et al. 10-year follow-up of diabetes incidence and weight loss in the Diabetes Prevention Program Outcomes Study. Lancet. 2009;374:1677-86.

87. Misra A. Prevention of type 2 diabetes: the long and winding road. Lancet. 2009;374:1655-6.

88. Misra A, Nigam P, Hills AP, Chadha DS, Sharma V, Deepak KK, et al. Consensus physical activity guidelines for Asian Indians. Diabetes Technol Ther. 2011.

89. Brown BD, Harris KJ, Harris JL, Parker M, Ricci C, Noonan C. Translating the diabetes prevention program for Northern Plains Indian youth through community-based participatory research methods. Diabetes Educ. 2010;36:924-35.

90. Chowdhury AM, Helman C, Greenhalgh T. Food beliefs and practices among British Bangladeshis with diabetes: implications for health education. Anthropol Med. 2000;7:219-26.
91. Macaden L, Clarke CL. Risk perception among older South Asian people in the UK with type 2 diabetes. Int J Older People Nurs. 2006;1:177-81.

92. Samanta A, Campbell JE, Spaulding DL, Neogi SK, Panja KK, Burden AC. Eating habits in Asian diabetics. Diabet Med. 1986;3:283-4.

93. Aslam M, Healy MA. Compliance and drug therapy in fasting Moslem patients. J Clin Hosp Pharm. 1986;11:321-5.

94. Hawthorne K, Mello M, Tomlinson S. Cultural and religious influences in diabetes care in Great Britain. Diabet Med. 1993;10:8-12.

95. Mather HM. Diabetes in elderly Asians. J R Soc Med. 1994;87:615-6.

96. Hawthorne K. Asian diabetics attending a British hospital clinic: a pilot study to evaluate their care. Br J Gen Pract. 1990;40:243-7.

97. Venkataraman K, Kannan AT, Kalra OP, Gambhir JK, Sharma AK, Sundaram KR, et al. Diabetes self-efficacy strongly influences actual control of diabetes in patients attending a tertiary hospital in India. J Community Health. 2011.

98. Steyn NP, Mann J, Bennett PH, Temple N, Zimmet P, Tuomilehto $\mathrm{J}$, et al. Diet, nutrition and the prevention of type 2 diabetes. Public Health Nutr. 2004;7:147-65. 